\title{
ARCHITECTURE AND CONSTRUCTION
}

\section{STUDY OF STRESSED-DEFORMED STATE OF THE POLYGONAL ARCH COVERINGS OF WOOD}

\author{
PG. O. V. Boiko, \\ Phd. A. O. Boiadzhi, \\ Phd. O. M. Korshak \\ Odessa state academy of civil engineering and architecture, Ukraine.
}

DOI: https://doi.org/ 10.31435/rsglobal_ws/31012019/6292

\section{ARTICLE INFO}

Received: 21 November 2018

Accepted: 22 January 2019

Published: 31 January 2019

\section{KEYWORDS}

polygonal arch coverings,

wooden I-beams,

stress-strain state

\begin{abstract}
In this work the use of wooden I-beams with OSB wall as the load bearing elements for polygonal arch coverings of buildings of various spans are considered. Special steel connecting pieces can shape the polygonal arch coverings. Calculations of the constructions with a span of 12 and 18 meters and an analysis of their stress-strain state are given.
\end{abstract}

Citation: O. V. Boiko, A. O. Boiadzhi, O. M. Korshak. (2019) Study of Stressed-Deformed State of the Polygonal Arch Coverings of Wood. World Science. 1(41), Vol.1. doi: 10.31435/rsglobal_ws/31012019/6292

Copyright: (C) 2019 O. V. Boiko, A. O. Boiadzhi, O. M. Korshak. This is an open-access article distributed under the terms of the Creative Commons Attribution License (CC BY). The use, distribution or reproduction in other forums is permitted, provided the original author(s) or licensor are credited and that the original publication in this journal is cited, in accordance with accepted academic practice. No use, distribution or reproduction is permitted which does not comply with these terms.

Introduction. Currently it is observed a steady increase in the production of I-beam wooden beams (IWB) with a wall of OSB in Ukraine. It significantly has reduced the import of these products and has filled the domestic construction market with light and efficient designs of its own production. We should notice that composite beams with elements from the OSB board are increasingly used in the frameworks of low-rise buildings, as well as the quality of elements of coatings and ceilings in stone buildings. The ease and low cost of such constructions open up new areas of using them in construction [1].

Analysis of recent researches and publications. Analysis of the structural forms of composite beams, the features of their application in the building framework along with existing methods for calculating composite wooden beams, indicates that when certain requirements to IWB $[2,3]$, they can be used in polygonal arch coverings (Fig. 1) by span of 12-18 m.

Determination of the purpose and objectives of the study. The authors of the study have set a goal to identify and analyze the stress-strain state of polygonal arch structures with different versions of their structural elements.

The main part of the study. Calculation of two types of coverings: without supports for a 12 $\mathrm{m}$ of span (Fig. 1a) and with supports for $18 \mathrm{~m}$, (Fig. 1b) showed that with the support of a polygonal arch without puffs on the walls of the building, the efforts of the stay brace are perceived by the walls of the building. The moments of flection that arise in this case in the walls cause tensile forces on the inner sides of the cross sections of these walls. In order to perceive these forces, additional reinforcement must be selected in the reinforced concrete walls; in the brick walls such efforts are unacceptable. Thus, when using such structures, it is necessary to use stiffen-arched girders or to provide other solutions aimed at removing the action of the expansion on the walls [4]. 
The presence of load-bearing walls between the supports of the structure allows the installation of additional racks and to increase the rigidity of the structure or to ease it. Also, the additional racks can be installed on the gables of the building, if it is necessary $[5,6]$.
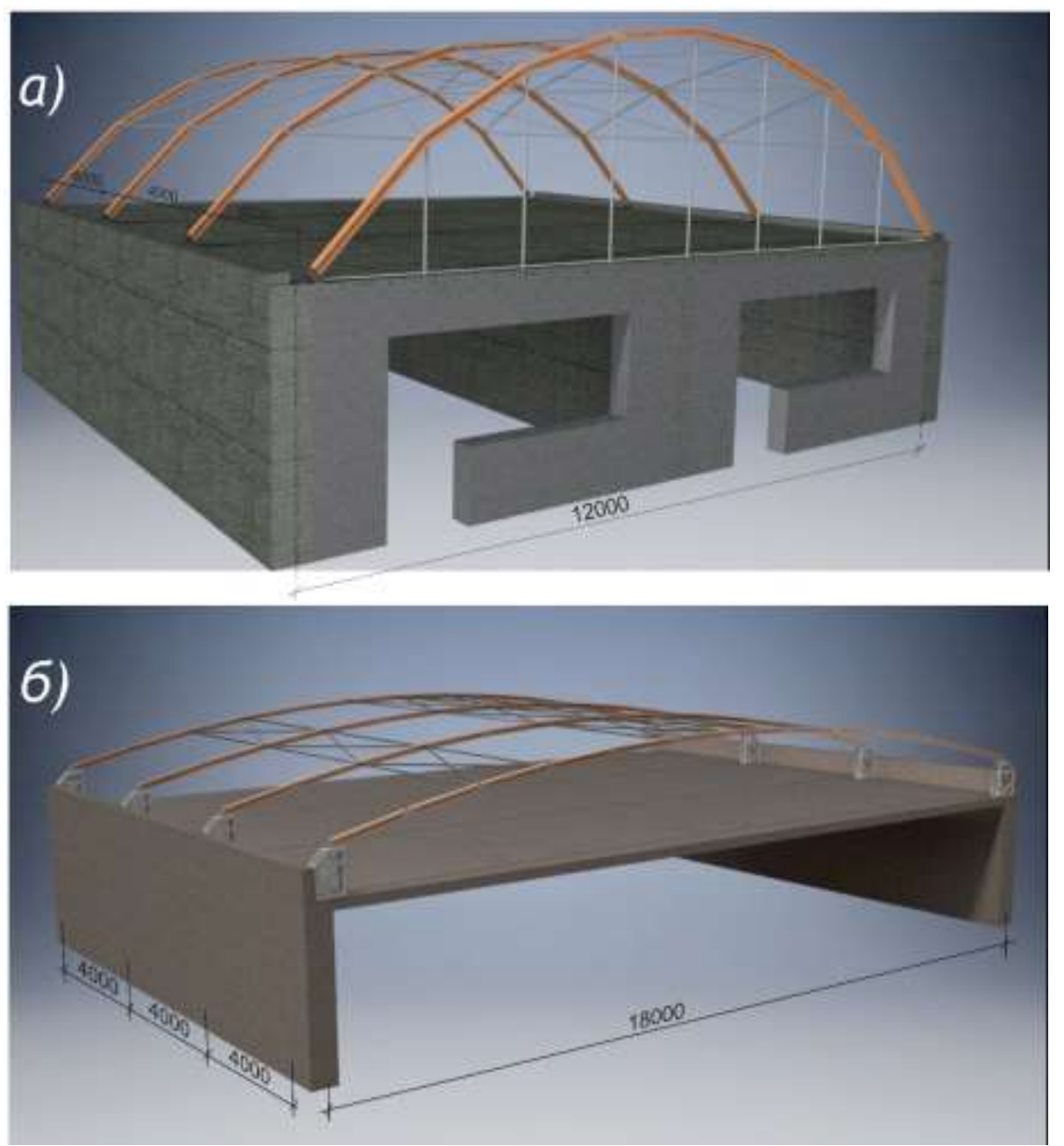

Fig.1. Polygonal vaulted coverings: a) by the span of $12 \mathrm{~m}$; b) by the span of $18 \mathrm{~m}$.

The considered polygonal coverings by the span of $12 \mathrm{~m}$ are made from wooden I-beams with an OSB-wall of the following sizes: beam height is $120 \mathrm{~mm}$, belt height is $40 \mathrm{~mm}$, belt width is $90 \mathrm{~mm}$, wall thickness of OSB is $10 \mathrm{~mm}$, length is $1400 \mathrm{~mm}$ and more, connected by paired metal plates [1]; when the span is increased to $18 \mathrm{~m}$, the dimensions of the booms are preserved, and the height of the wall needs to be doubled to ensure the rigidity of the coating structure.

The most common structural form of a composite beam with elements from the OSB board is a beam with solid wood booms, in which the wall of the OSB board is pasted into a groove arranged in the girdle of the beam. The disadvantages of this design form are the need for special equipment for the device grooves and presses to withstand the structure of the beam for the period of drying glue [7].

In the laboratory of wooden structures of OSACEA, tests of composite wooden beams with a span of 2.4 meters of the following structural solution were carried out: a kefa-fiber beam with a flat wall pasted into the groove in shelves of solid wood (Fig. 2); Plywood beam with a flat wall and with belts of wooden bars glued to the sides of the wall; Plywood beam with a wall pasted into the groove in the shelves of glued wood; a composite beam with belts of wooden bars connected to the wall from the OSB on the screws. For the test composite wooden beams were calculated theoretical deflection and maximum load capacity, using existing normative method of calculation of State building standards. 


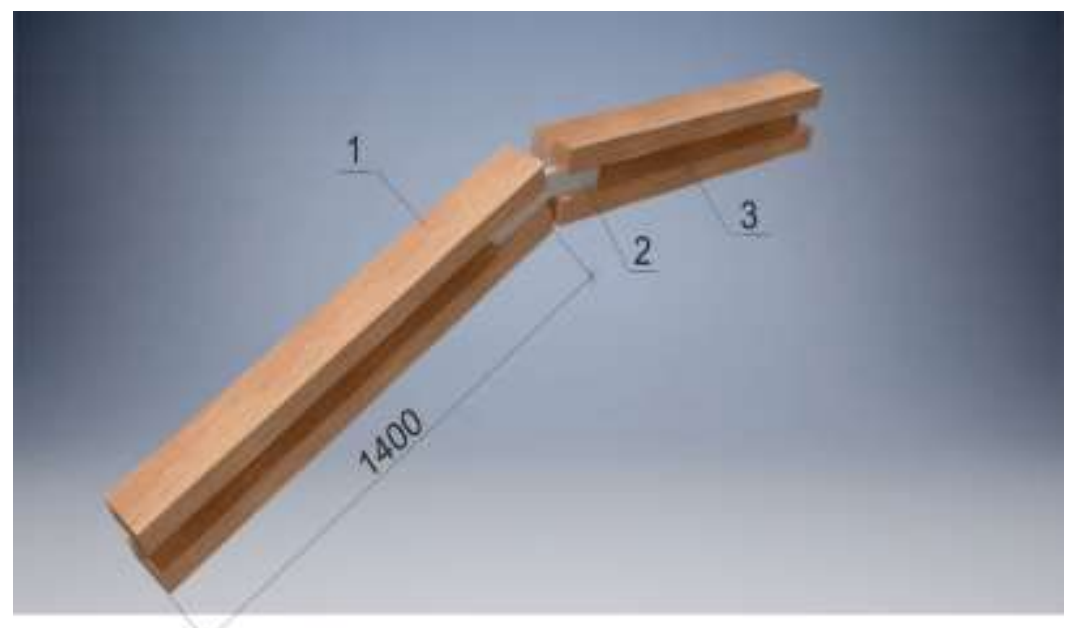

Fig.2 Wooden I-beams (IWB): a) beam; b) connection joints

1- shelf of the beam $(90 \times 40 \mathrm{~mm}) ; 2$ - connecting element; 3-wall from OSB $(10 \mathrm{~mm})$

The results of the numerical calculation are presented in the form of isopoles of stress distribution (Fig. 3) and displacements in the calculated beam model (Fig. 4). According to the type of stress distribution in the elements of the structure, the following can be said: normal stresses reach the maximum values of 1/4 span in the junction of the rectilinear structural elements and are close to the design tensile strength - compression of the OSB plate with a thickness of $10 \mathrm{~mm}$ and decrease to the middle of the span of the arch; the tangential stresses in the wall elements are 4-5 times lower than the normal stresses with a maximum on the supports and in the places where the load is applied.

For increase the strength of the walls from the OSB and to eliminate their brittle fracture, the walls were reinforced with thin metal grids.

Conclusions. The carried out theoretical, analytical and numerical studies have shown the possibility of using IWB with a wall from OSB in the construction of coatings not only of rectilinear, but also various polygonal outlines. Calculations have showed acceptable reserve factors for such structures.
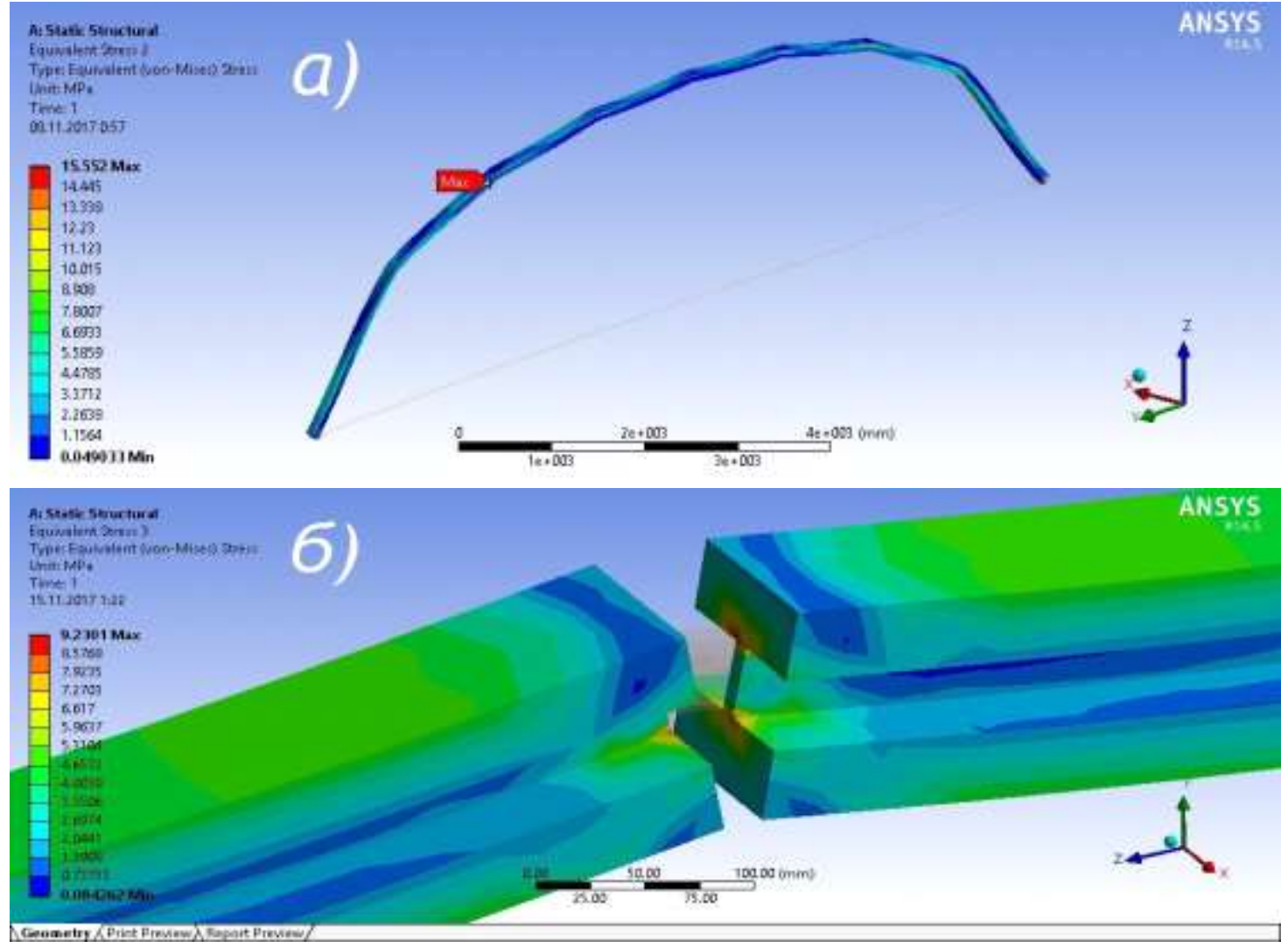

Fig. 3. Isopoles of equivalent stresses in wooden elements of arch structure by the span of $12 \mathrm{~m}$ a) throughout the structure; $b$ ) in the most loaded joints 


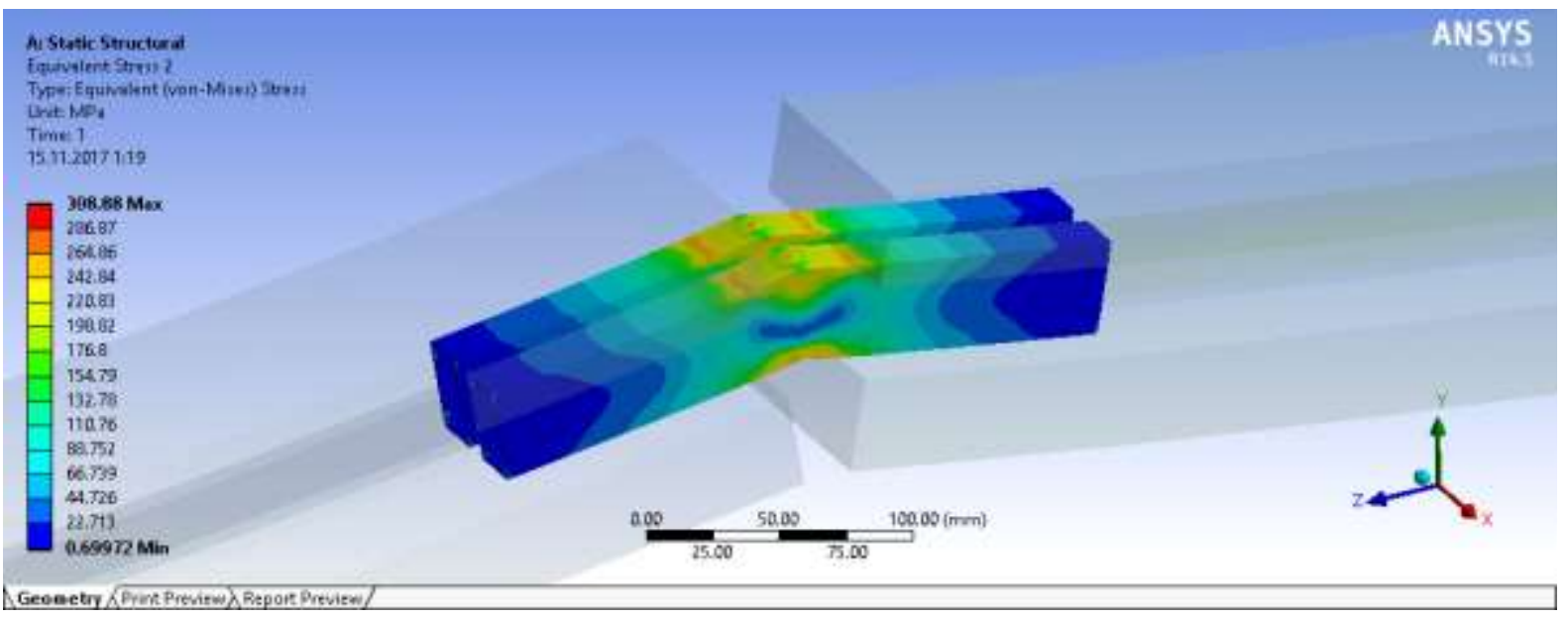

Fig. 4. Isolates of equivalent stresses in steel structural elements

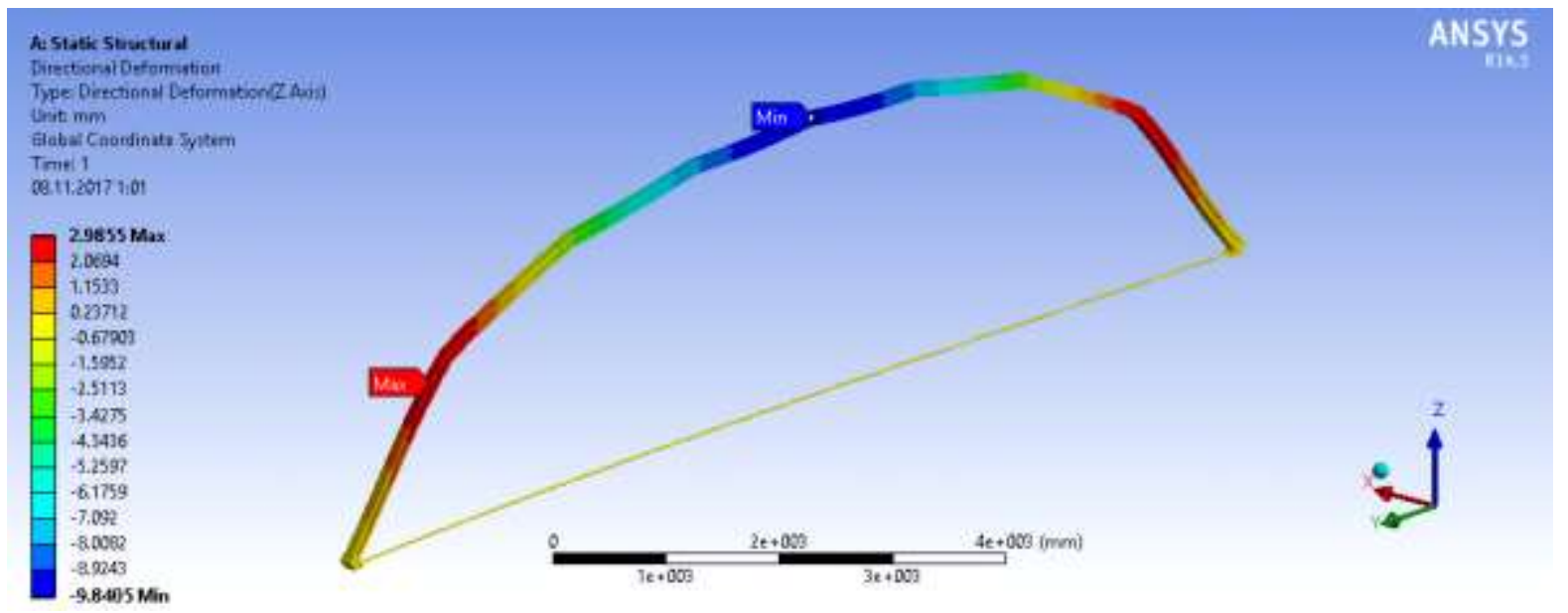

Fig. 5. Isolation of movement in an arched structure with a span of $12 \mathrm{~m}$

To determine the actual stress-strain state of the structure, experimental studies of models of polygonal arch constructions are conducted in the laboratory of the Department of Metal, Wooden and Plastic Constructions of OSACEA.

\section{REFERENCES}

1. Wooden I-beams with end-type nodes for the device of polygonal coverings of the cover $12 \ldots 18 \mathrm{~m}$. / V. V. Stoyanov, O.M. Korshak, O. V. Boiko, A. V. Chuchmai. // Modern building constructions from metal and wood. - 2017. - №1. - P. 56-62.

2. Stoyanov V.V. The Endpoint of Two-Tone Wooden Beams » Mar 02, 2017 No. 5043/ 3A / 17 registration number of the application - 24701663 / V.V. Stoyanov, O.V. Boiko. // patent. - 2017

3. Stoyanov V.V. Double-beam beams with wooden belts and OSB wall / V.V. Stoyanov, O. M. Korshak. // Woodworking. - 2009. - №6. - P. 17-30.

4. Martynets D.V. Glued wooden constructions / D.V. Martynets. - Moscow: Cartographer, 1975. - 52 p.

5. Lomakin A. D. Glued wooden constructions in agricultural buildings / A. D. Lomakin, D. V. Martynets. Moscow: Stroyizdat, 1982. - 103 p.

6. Kuznetsov I.L. Lightweight structures of arched buildings (Research, development, and implementation): diss. doc. tech Sciences: 05.23.01 / Kuznetsov Ivan Leonidovich - Kazan, 1995. - 310 p.

7. Rachera P. Effect of web stiffness on the bending behaviour of timber composite I-beams / P. Rachera, J. Bocquetb, A. Bouchaira. // Materials \& Design. - 2007. - P. 844-849. 